\title{
Granulomatous Pneumocystis jiroveci pneumonia associated with immune reconstituted HIV
}

\author{
Natasha F Sabur MD¹, Margaret M Kelly MB ChB PhD², M John Gill MB ChB MSc${ }^{1}$, \\ Martha D Ainslie MD MSc ${ }^{3}$, Sachin R Pendharkar MD MSc${ }^{1}$
}

\begin{abstract}
NF Sabur, MM Kelly, MJ Gill, MD Ainslie, SR Pendharkar. Granulomatous Pneumocystis jiroveci pneumonia associated with immune reconstituted HIV. Can Respir J 2011;18(6):e86-e88.

Pneumocystis jiroveci pneumonia uncommonly presents with pulmonary nodules and granulomatous inflammation. An unusual case of granulomatous $P$ jiroveci pneumonia in an HIV patient with a CD4 $4^{+}$lymphocyte count of greater than 200 cells $/ \mathrm{mm}^{3}$, occurring in the context of immune reconstitution with highly active antiretroviral therapy, is described. The case highlights the importance of establishing this diagnosis to institute appropriate therapy.
\end{abstract}

Key Words: HIV/AIDS; Immune reconstitution disease; Multiple pulmonary nodules; Pneumocystis jiroveci

\section{CASE PRESENTATION}

A 40-year-old man presented with progressive cough, dyspnea and $20 \mathrm{~kg}$ weight loss over several weeks. Chest imaging revealed bilateral ground-glass infiltrates, and Pneumocystis jiroveci pneumonia (PCP) was confirmed by bronchoalveolar lavage (BAL) analysis. The patient was subsequently found to be positive for HIV, with a CD4 ${ }^{+}$ lymphocyte count of 16 cells $/ \mathrm{mm}^{3}$, an HIV viral load $>5 \times 10^{6}$ copies/ $\mathrm{mL}$ and evidence of HIV dementia. He responded to a 21-day course of trimethoprim-sulfamethoxazole and prednisone, and was started on highly active antiretroviral therapy (HAART) shortly before completing treatment for PCP. Two months after initiating HAART, his CD4 ${ }^{+}$ count had increased to 359 cells $/ \mathrm{mm}^{3}$ and his HIV viral load was $3.1 \times 10^{4}$ copies $/ \mathrm{mL}$. Due to an allergic reaction to sulfamethoxazole, PCP prophylaxis was discontinued. A routine chest radiograph performed four months later revealed multiple bilateral pulmonary nodules (Figure 1). Subsequent chest computed tomography (CT) scans confirmed the presence of multiple homogeneous and noncalcified pulmonary nodules, several of which were cavitary. These were most prominent in the lung apices (Figure 2). The patient was asymptomatic, had been compliant with therapy and had a CD4+ count of 266 cells $/ \mathrm{mm}^{3}$.

During the following year, the patient developed malaise, cough and wheeze. His CD4 ${ }^{+}$count had been consistently $>250$ cells $/ \mathrm{mm}^{3}$ for the previous seven months, with undetectable HIV viral loads. Chest CT revealed progression of the pulmonary nodules. Bronchoscopy with BAL and transbronchial biopsy was performed, in addition to transthoracic needle biopsy. Direct fluorescent antibody testing for pneumocystis was negative on all specimens, and bacterial culture, cytology and acid-fast bacillus (AFB) smears were consistently negative. Thoracoscopic lung biopsy was ultimately performed, and confirmed the presence of necrotizing granulomas containing Pneumocystis organisms surrounded by a hyalinized capsule (Figure 3). Treatment was initially deferred because the patient's symptoms were mild and not clearly attributable to PCP infection. However, the patient's symptoms progressed to include drenching night sweats, worsening cough and progressive dyspnea. He was subsequently treated for PCP with atovaquone, despite a CD4 ${ }^{+}$count of 374 cells $/ \mathrm{mm}^{3}$. Within two weeks, his symptoms resolved, his weight increased and his diffusing capacity for carbon monoxide increased from $62 \%$ predicted to $87 \%$ predicted. A repeat chest CT scan three months later showed no significant change in the pulmonary nodules.

\section{Une pneumonie granulomateuse à Pneumocystis jiroveci associée à un $\mathrm{VIH}$ en reconstitution immunitaire}

La pneumonie à Pneumocystis jiroveci s'associe parfois à des nodules pulmonaires et à une inflammation granulomateuse. Les auteurs décrivent un cas inhabituel de pneumonie granulomateuse à $P$ jiroveci chez un patient atteint du VIH dont la numération lymphocytaire CD4 ${ }^{+}$était supérieure à 200 cellules $/ \mathrm{mm}^{3}$, dans le contexte d'une reconstitution immunitaire par thérapie antirétrovirale hautement active. Ce cas fait ressortir l'importance de bien poser le diagnostic pour amorcer le bon traitement.

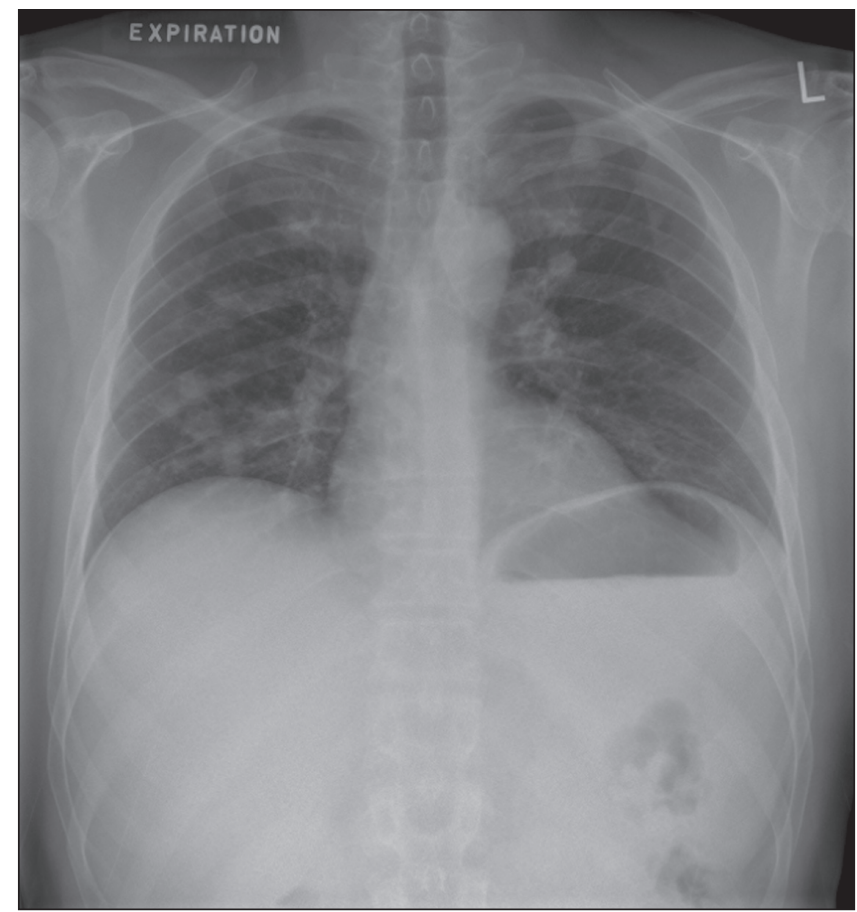

Figure 1) Chest radiograph revealing multiple bilateral pulmonary nodules in a 40-year-old HIV-positive man

\section{DISCUSSION}

Granulomatous PCP is an uncommon form of pneumocystis infection, occurring in only $3 \%$ to $5 \%$ of patients (1). Cases have most commonly been described in HIV patients with $\mathrm{CD}^{+}$counts $<200$ cells $/ \mathrm{mm}^{3}$, and rarely in other immunocompromised patients (2). An insidious presentation is the rule, with minimal systemic or respiratory symptoms. Risk factors for the development of granulomatous PCP include PCP prophylaxis with aerosolized pentamidine, active malignancy, recent corticosteroid use and immune reconstitution disease $(1,2)$. BAL and transbronchial biopsy often fail to reveal organisms, and the diagnosis

${ }^{1}$ Department of Medicine; ${ }^{2}$ Department of Pathology and Laboratory Medicine, University of Calgary, Calgary, Alberta; ${ }^{3}$ Department of

Respirology, University of Manitoba, Winnipeg, Manitoba

Correspondence: Dr Sachin R Pendharkar, Department of Medicine, University of Calgary, 7007-14th Street Southwest, Calgary,

Alberta T2V 1P9. Telephone 403-943-8660, fax 403-943-8666, e-mail pendharkar.sachin@gmail.com 


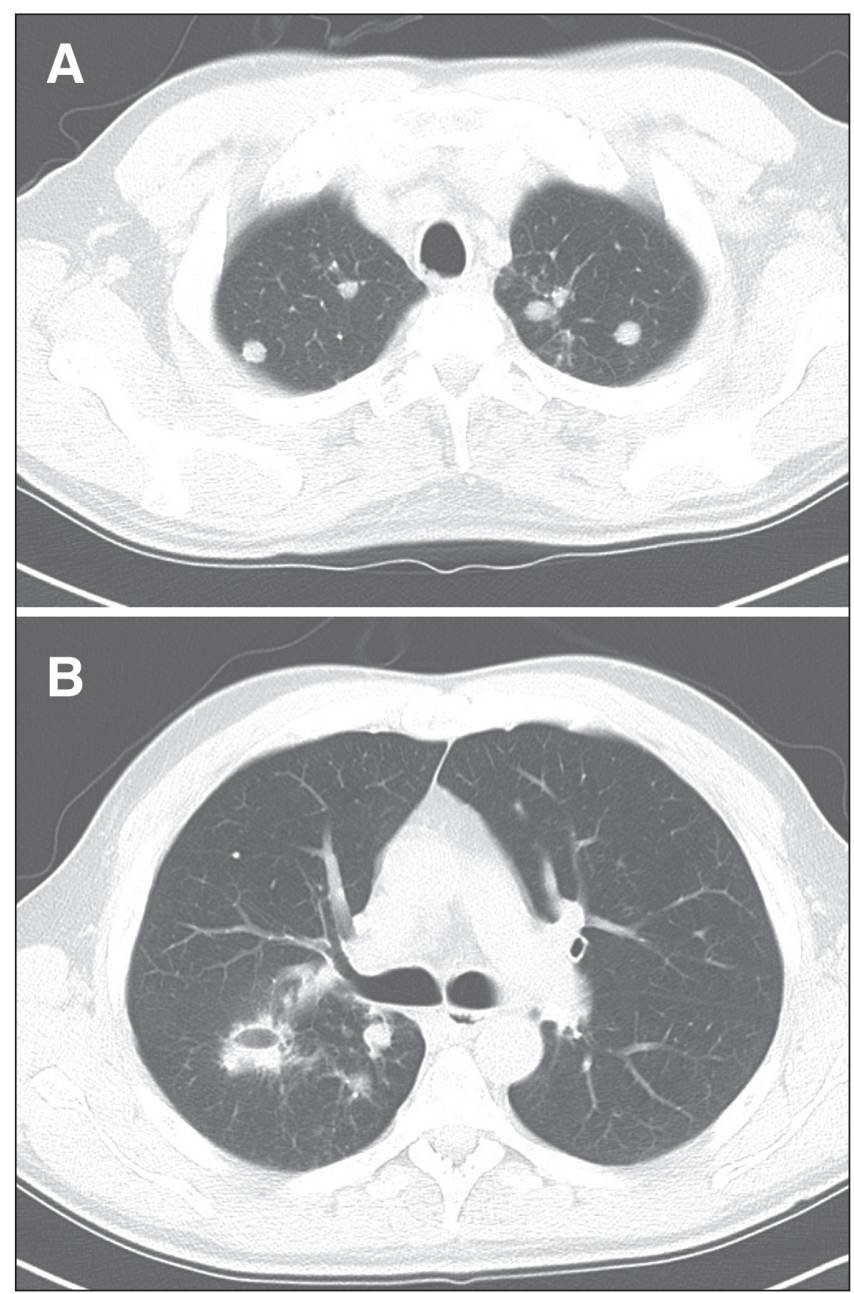

Figure 2) Chest computed tomography scan of the patient demonstrating bilateral pulmonary nodules more prominent in the apices (A), including a cavitating nodule (B)

is often made on open lung biopsy or postmortem. Biopsy specimens typically reveal Pneumocystis organisms within hyalinized granulomas.

Immune reconstitution disease (IRD) is a paradoxical worsening of a pre-existing opportunistic infection in HIV-positive individuals after the initiation of HAART, despite improvement in markers of HIV infection. It occurs in $10 \%$ to $25 \%$ of patients receiving HAART, often within eight weeks of therapy, and is most commonly seen with mycobacterial infections (3). IRD with PCP has been rarely reported, occurring two weeks to seven months after initiation of HAART $(4,5)$. Risk factors for IRD include a pretreatment CD4 ${ }^{+}$ count $<50$ cells $/ \mathrm{mm}^{3}$, a brisk $\mathrm{CD}^{+}{ }^{+}$recovery of two- to four-fold in the first 12 months of therapy or a rapid decrease in HIV viral load after initiation of HAART (6). Pathogenic mechanisms include immune recognition of antigens associated with ongoing infection or an inflammatory response to nonreplicating antigens from previous infection $(6,7)$. Granuloma formation is characteristic due to $T$ lymphocyte activation (8). The inflammatory reaction is responsive to a combination of glucocorticoids and anti-inflammatories, whereas IRD occurring as a result of active infection requires treatment with antimicrobials. HAART should be discontinued if the inflammatory response is life threatening (6).

PCP colonization is defined by the presence of Pneumocystis DNA in the respiratory specimens of patients without clinical PCP infection. Colonization is detected with polymerase chain reaction assays targeting the large subunit of mitochondrial ribosomal RNA (9). PCP colonization is seen in $20 \%$ of healthy adults (10), $44 \%$ of non-HIV

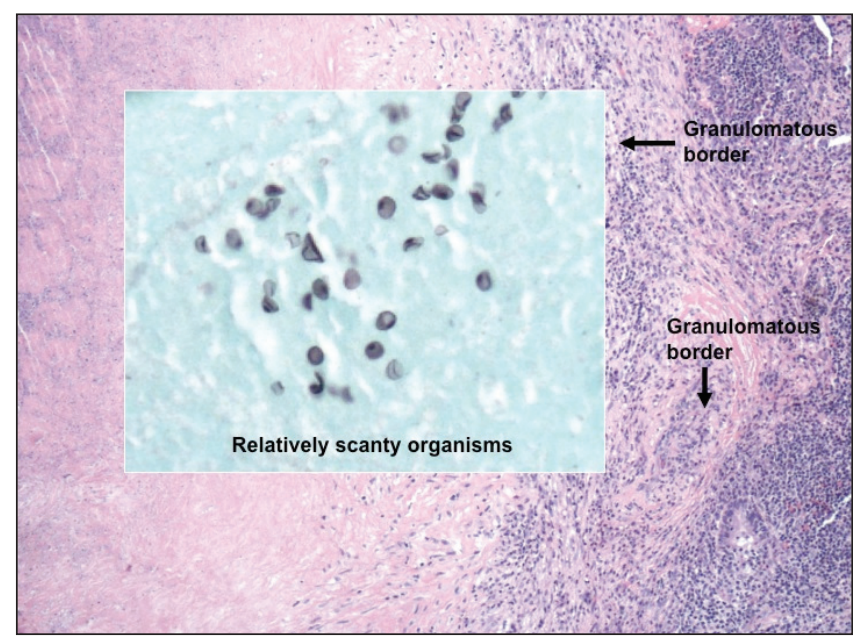

Figure 3) Thoracoscopic lung biopsy of the nodules demonstrates necrotizing granulomas containing pneumocystis organisms surrounded by a hyalinized capsule

immunocompromised individuals and $46 \%$ of HIV-infected hosts without active PCP (11). Risk factors for PCP colonization include HIV infection, corticosteroid use and chronic lung disease (9). It is unclear whether PCP colonization represents the presence of active organisms and, as such, predisposes patients to subsequent PCP infection.

We hypothesize that our patient developed an immune response to pneumocystis antigens remaining in the lung after treatment of primary pneumocystosis. The lysis of nodules during surgery likely resulted in the release of PCP antigens, intensifying the immune response and causing a progression of symptoms. Clinical improvement with directed antimicrobial therapy is evidence of active infection and not merely PCP colonization - either alone or in association with IRD. The patient's presentation is unique in that there was a significant delay in symptoms after the radiographic demonstration of pulmonary nodules, without a clear inciting factor for the development of symptoms and in the setting of an adequate $\mathrm{CD} 4^{+}$count. The present case highlights the need to consider PCP in all HIV patients, even those with an unusual presentation; although establishing a diagnosis can be challenging, it is critical to provide appropriate therapy at the onset of infectious or immune complications.

DISCLOSURES: This work was performed at the University of Calgary, Calgary, Alberta. All authors have participated in this research, and have reviewed and agreed with the content of the article.

CONFLICTS OF INTEREST/FUNDING: The authors have no financial disclosures or conflicts of interest to declare.

\section{REFERENCES}

1. Bondoc AYP, White DA. Granulomatous Pneumocystis carinii pneumonia in patients with malignancy. Thorax 2002;57:435-37.

2. Totet A, Duwat H, Daste G, et al. Pneumocystis jiroveci genotypes and granulomatous pneumocystosis. Med Mal Infect 2006;36:229-31.

3. Battegay M, Nuesch R, Hirschel B, et al. Immunological recovery and antiretroviral therapy in HIV-1 infection. Lancet Infect Dis 2006;6:280-87.

4. Barry SM, Lipman MCI, Deery AR, et al. Immune reconstitution pneumonitis following Pneumocystis carinii pneumonia in HIV-infected subjects. HIV Med 2002;3:207-11.

5. Takahashi T, Nakamura T, Iwamoto A. Reconstitution of immune responses to Pneumocystis carinii pneumonia in patients with HIV infection who receive highly active antiretroviral therapy. Res Commun Mol Pathol Pharmacol 2002;112:59-67. 


\section{Sabur et al}

6. Hirsch HH, Kaufmann G, Sendi P, et al. Immune reconstitution in HIV-infected patients. Clin Infect Dis 2004;38:1159-66.

7. Crothers K, Huang L. Recurrence of Pneumocystis carinii pneumonia in an HIV-infected patient: Apparent selective immune reconstitution after initiation of antiretroviral therapy. HIV Med 2003;4:346-49.

8. Chen F, Sethi G, Goldin R, et al. Concurrent granulomatous Pneumocystis carinii and Mycobacterium xenopi pneumonia: An unusual manifestation of HIV immune reconstitution disease. Thorax 2004;59:997-99.
9. Davis JL, Welsh DA, Beard CB, et al. Pneumocystis colonization is common among hospitalized HIV infected patients with non-Pneumocystis pneumonia. Thorax 2008;63:329-34.

10. Medrano FJ, Montes-Cano M, Conde M, et al. Pneumocystis jirovecii in general population. Emerg Infect Dis 2005;11:245-50.

11. Morris A, Kingsley LA, Groner G, et al. Prevalence and clinical predictors of Pneumocystis colonization among HIV-infected men. AIDS 2004;18:793-98. 


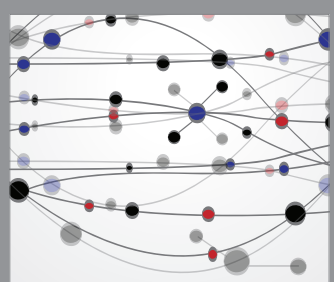

The Scientific World Journal
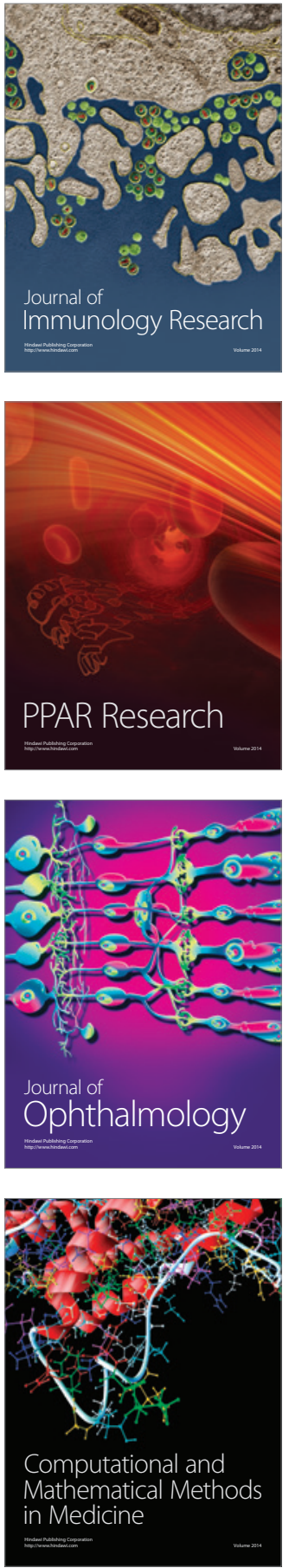

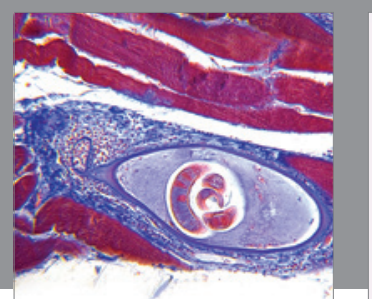

Gastroenterology Research and Practice

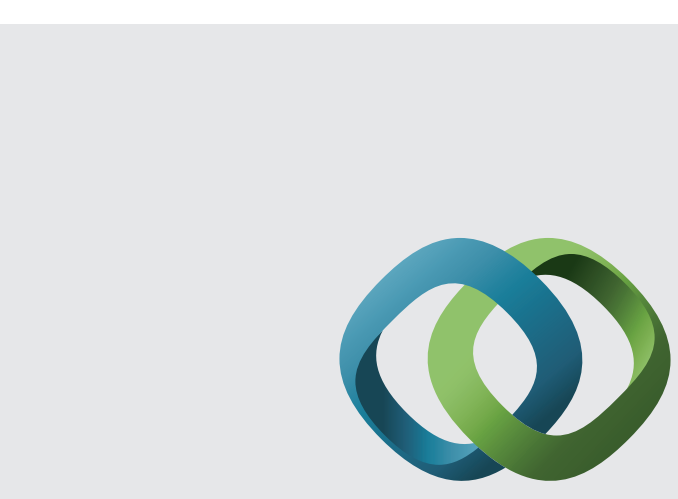

\section{Hindawi}

Submit your manuscripts at

http://www.hindawi.com
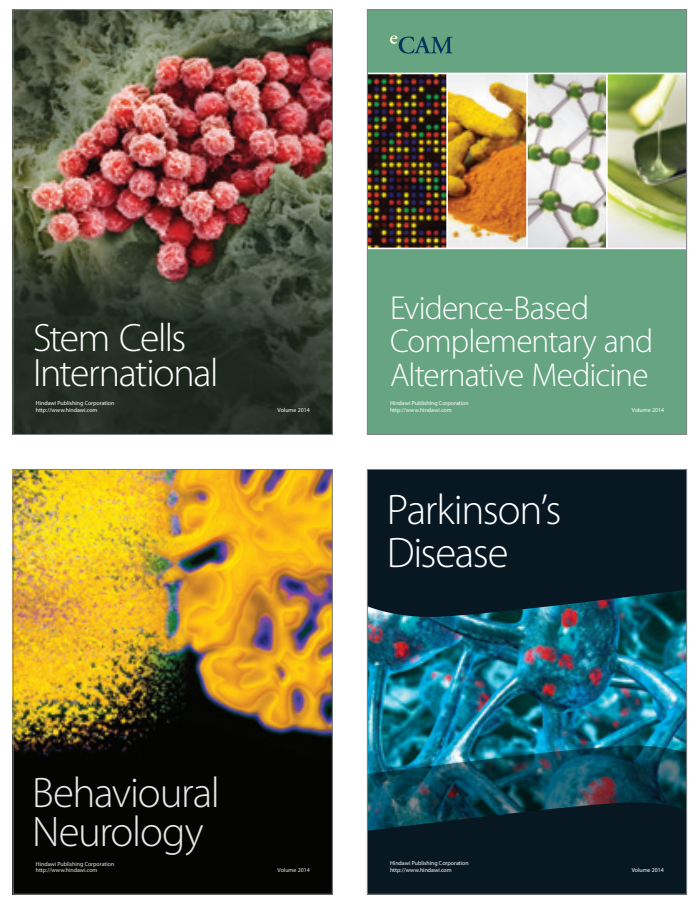
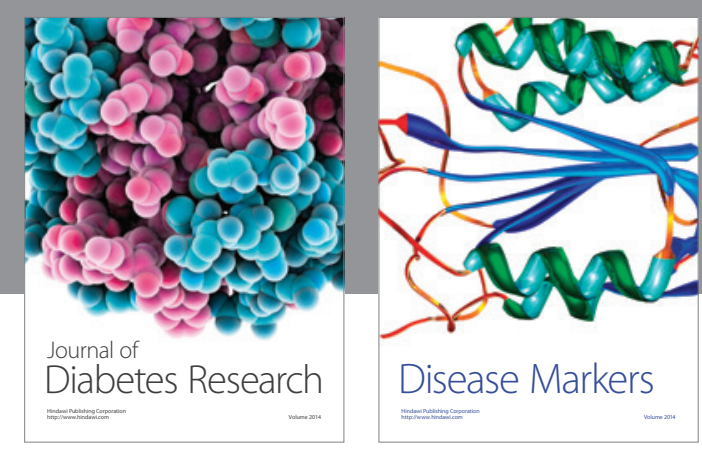

Disease Markers
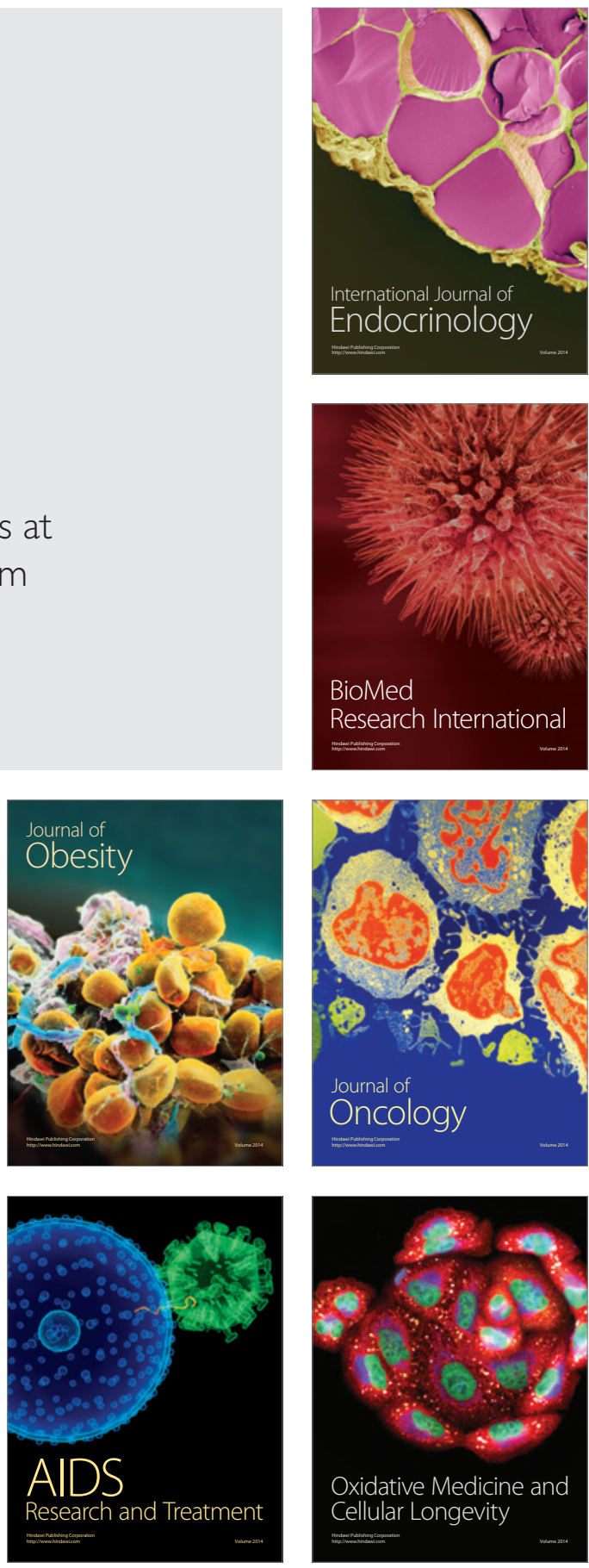